\title{
The effects of some tumor markers on human erythrocyte (HCA-I and HCA-II), bovine erythrocyte (BCA) and bovine lung (CA-IV) carbonic anhydrase enzyme activities in vitro
}

\author{
Demir $\mathrm{N}^{1}$, Nadaroglu $\mathrm{H}^{2}$, Gungor $\mathrm{AA}^{3}$, Demir $\mathrm{Y}^{1,4}$ \\ Faculty of Sciences, Chemistry Department, Mugla University, 48000, Mugla, Turkey. demirn@yahoo.com
}

\begin{abstract}
Objective: The influence of prostatic acid phosphatase (PAP) and human chorionic gonadotropin (HCG), tumor markers have been investigated on human erythrocyte carbonic anhydrase (HCA-I and HCA-II) and bovine erythrocyte (BCA) and bovine lung carbonic anhydrase (CA-IV) in vitro.

Background: Tumor markers are substances that can often be detected in higher-than-normal amounts in the blood, urine, or body tissues of some patients with certain types of cancer. Tumor markers are produced either by the tumor itself or by the body in response to the presence of cancer or certain benign (noncancerous) conditions. In addition to their role in cancer diagnosis, some tumor marker levels are measured before treatment to help doctors plan appropriate therapy.

Results and conclusion: All of the tumor markers were determined to have inhibition effect, on human CA-I, CAII, bovine erythrocyte CA (BCA) and bovine lung CA-IV isoenzymes. The effect of each tumor marker on CA was investigated by Wilbur-Andersen method modified by Rickly et al Inhibition effects of two different tumor markers on human CA-I, CA-II, bovine erythrocyte CA (BCA) and bovine lung CA-IV isoenzymes were determined by using the $\mathrm{CO}_{2}$-Hydratase method by plotting activity \% vs (tumor markers). I ${ }_{50}$ values of tumor markers exhibiting inhibition effects were found by means of these graphs (Tab.1, Fig. 2, Ref. 20). Text in PDF www.elis.sk. Key words: tumor markers, carbonic anhydrase, HCA-I, HCA-II, BCA, CA-IV, Zn²+.
\end{abstract}

\section{Introduction}

Carbonic anhydrase (carbonate hydrolyase, EC 4.2.1.1) isozymes are a family of zinc metalloenzymes which catalyze the interconversion of $\mathrm{CO}_{2}$ and $\mathrm{HCO}_{3}^{-}$(1).

$$
\mathrm{CO}_{2}+\mathrm{H}_{2} \mathrm{O} \rightleftarrows \mathrm{HCO}_{3}^{-}+\mathrm{H}^{+}
$$

The enzyme, discovered about 70 years ago $(2,3)$, is abundantly present in mammalian red blood cells and to a lesser extent in different types of tissues and secretory organs (5-6). In addition, carbonic anhydrase from plant, yeast and bacteria have been reported and partially characterized (5-11). The important roles of the enzyme in various cell types have been extensively reviewed $(5,6)$. At present, approximately 14 isozymes (I-XIV) are reported and found to be distributed throughout the living organisms $(5,6,11)$.

In man, CA-IV has been identified in the microvilli and basal infoldings of renal tubular cells, and this isoform has recently

${ }^{1}$ Faculty of Sciences, Chemistry Department, Mugla University, Mugla, Turkey, ${ }^{2}$ Department of Food Technology, Erzurum Vocational Training School, Ataturk University, Erzurum, Turkey, ${ }^{3}$ Department of Chemical Technology, Erzurum Vocational Training School, Ataturk University, Erzurum, Turkey, and ${ }^{4}$ Department of Chemistry, Faculty of Science, University of Mehmet Akif Ersoy, Burdur, Turkey

Address for correspondence: N. Demir, MD, Mugla University, Faculty of Sciences, Chemistry Department, 48000, Mugla, Turkey.

Phone: +90.442.2314439, Fax: +90.442.2360948 been purified and characterized (12). An apparently homologous enzyme (13) has also been purified from human lung. It is proposed that the CA-IV isoenzyme is primarily responsible for the re-absorption of $\mathrm{HCO}_{3}{ }^{-}$in the proximal tubule and is involved in the formation of lung liquid during fetal life.

The carbonic anhydrase enzyme taken from cow lung has already been partially purified (12). The process of purification carried out at our laboratory produced some new and significant results. The present study made it possible to find new data about CA-IV enzyme which is of vital importance for respiration which would otherwise be left incomplete. A new definition for this enzyme is presented as a result of our experiment.

The critical enzyme can be thought to be affected by tumor markers, which are widely consumed. This in vitro study was planned in order to investigate the effect of tumor markers with or without alcohol on the enzyme, which is important in respect of human health.

\section{Materials and methods}

Purification of carbonic anhydrase from human erythrocytes

Erythrocytes were purified from human blood obtained from Blood Center of Research Hospital at Atatürk University. The blood samples were centrifuged at $1500 \mathrm{rpm}$ for $20 \mathrm{~min}$ and the plasma and buffy coat were removed. After the packed red cells had been washed with $\mathrm{NaCl}(0.9 \%)$ three times, the erythrocytes 
were hemolyzed with cold water. The ghost and intact cells were removed by centrifugation at $4{ }^{\circ} \mathrm{C}, 20,000 \mathrm{rpm}$ for $30 \mathrm{~min}$. The $\mathrm{pH}$ of hemolysate was brought to 8.5 with solid tris. The hemolysate was applied to the affinity column having a structure of Sepharose 4B-L-tyrosine-sulfonyamide and equilibrated with $25 \mathrm{mM}$ Tris$\mathrm{HCl} / 0.1 \mathrm{M} \mathrm{Na}_{2} \mathrm{SO}_{4}(\mathrm{pH} 8.5)$. The affinity gel was washed with a solution of $25 \mathrm{mM}$ Tris- $\mathrm{HCl} / 22 \mathrm{mM} \mathrm{Na}_{2} \mathrm{SO}_{4}(\mathrm{pH}$ 8.5). HCA-I and HCA-II isoenzymes were eluted with a solution of $1 \mathrm{M} \mathrm{NaCl} /$ $25 \mathrm{mM} \mathrm{Na}_{2} \mathrm{HPO}_{4}\left(\mathrm{pH} 6.3\right.$ ) and $0.1 \mathrm{M} \mathrm{NaCH}_{3} \mathrm{COO} / 0.5 \mathrm{M} \mathrm{NaClO}_{4}$ (pH 5.6) (14). The elutions were plotted by protein determination at $280 \mathrm{~nm}$ and $\mathrm{CO}_{2}$-hydratase activity and the purification was controlled with SDS-PAGE (15).

Preparation of carbonic anhydrase from bovine erythrocytes

Bovine blood was anticoagulated with $1.5 \mathrm{~mL}$ of ACD solution (22 $\mathrm{g}$ of sodium citrate dihydrate, $8 \mathrm{~g}$ of citric acid and $24 \mathrm{~g}$ of dextrose per liter) per $100 \mathrm{~mL}$ blood, and red blood cells were obtained and washed with saline. The cells were lysed with distilled water. The ghosts were removed by centrifugation. The hemolysate was applied to the affinity column, having a structure of Sepharose 4B-L-tyrosine-sulfonyamide and equilibrated with $25 \mathrm{mM}$ Tris- $\mathrm{HCl} / 0.1 \mathrm{M} \mathrm{Na}_{2} \mathrm{SO}_{4}(\mathrm{pH} 8.5)$. The affinity gel was washed with a solution of $25 \mathrm{mM}$ Tris- $\mathrm{HCl} / 22 \mathrm{mM} \mathrm{Na}_{2} \mathrm{SO}_{4}(\mathrm{pH}$ 8.5). BCA was eluted with a solution of $0.1 \mathrm{M} \mathrm{NaCH}_{3} \mathrm{COO} / 0.5$ $\mathrm{M} \mathrm{NaClO}_{4}$ ( $\mathrm{pH}$ 5.6) (14). The elutions were plotted by doing protein determination at $280 \mathrm{~nm}$ and $\mathrm{CO}_{2}$-hydratase activity and the purification was controlled with SDS-PAGE (15).

\section{Purification of carbonic anhydrase from bovine lung}

Samples about $250 \mathrm{~g}$ in weight from cow lung were taken during slaughtering at the Erzurum Municipal Slaughterhouse and rinsed into a solution of $0.9 \% \mathrm{NaCl}$. Firstly, a piece of lung was cut into smaller pieces, washed with physiological serum and then chopped in a blender. Approximately 60 liters of serum was used in order to eliminate erythrocytes from the medium. Washing was continued until achieving precipitation that was clear enough.

The sample of lung, entirely free of erythrocytes, was taken into $500 \mathrm{~mL}$ buffer of $0.05 \mathrm{M}$ Tris- $\mathrm{SO}_{4}(\mathrm{pH}$ 7.4) containing $1 \%$ Triton X-100 (2 mL per gram), dismembered by an ultrasonic dismembrator for 4 hours and then centrifuged for 30 minutes at $3000 \mathrm{xg}$. The precipitation was removed by filtering through fiberglass. The supernatant was treated with distilled water for 2 days and with $0.05 \mathrm{M}$ Tris- $\mathrm{SO}_{4}$ ( $\mathrm{pH}$ 7.4) buffer for dialysis. Then the homogenate was extracted by approximately $500 \mathrm{~mL} \mathrm{CCl}_{4}$ to eliminate the lipids from the medium and organic medium was removed. The $\mathrm{pH}$ of homogenate was brought to 8.7 by using solid Tris until it was prepared to be applied to column. The same af-

Tab. 1. The results of inhibition studies for HCG and PAP compounds on HCA-I, HCA-II, CA-IV and BCA.

\begin{tabular}{lcccc}
\hline Compound & HCA-I & HCA-II & CA-IV & BCA \\
& $\mathrm{I}_{50}(\mathrm{nM})$ & $\mathrm{I}_{50}(\mathrm{nM})$ & $\mathrm{I}_{50}(\mathrm{nM})$ & $\mathrm{I}_{50}(\mathrm{nM})$ \\
\hline HCG & $6.78 \times 10^{-2}$ & $6.79 \times 10^{-2}$ & $3.78 \times 10^{-2}$ & $2.59 \times 10^{-2}$ \\
PAP & $6.19 \times 10^{-2}$ & $6.08 \times 10^{-2}$ & $2.66 \times 10^{-2}$ & $1.55 \times 10^{-2}$ \\
\hline
\end{tabular}

finity gel was used for CA-IV. CA-IV was eluted with a solution of $0.1 \mathrm{M} \mathrm{NaCH}_{3} \mathrm{COO} / 0.5 \mathrm{M} \mathrm{NaClO}_{4}$ (pH 5.6) $(13,14)$. Protein concentration and activity were determined (16). Purification was controlled with SDS-PAGE (15).

\section{Determination of carbonic anhydrase activity and effect of tumor markers on isoenzymes}

Carbonic anhydrase activity and effect of tumor markers were assayed by hydration of $\mathrm{CO}_{2}$ measured by the method of Rickli et al (17) and Wilbur-Anderson with bromothymol blue as indicator. $\mathrm{CO}_{2}$-Hydratase activity as enzyme unit (EU) was calculated by the equation $\left(t_{0}-t_{c} / t_{c}\right)$ where $t_{o}$ and $t_{c}$ are the times for $\mathrm{pH}$ change in non-enzymatic (buffer) and enzymatic reaction, respectively.

\section{Determination of $I_{50}$ values}

The values of $I_{50}$ (inhibitor concentration reduced the enzyme activity by $50 \%$ ) have been determined graphically using five different inhibitor concentrations. For hormones showing inhibition effect, the values of $\mathrm{I}_{50}$ with diagram of activity percent-(I] were calculated.

\section{Results}

Many chemicals at a relatively low dosage affect the metabolism of biota by altering normal enzyme activity, particularly inhibiting specific enzymes (18). The effects can be dramatic and systemic (19). Although prostatic acid phosphatase (PAP) and human chorionic gonadotropin (HCG) are used, reduction in marker concentration indicates effective therapy, and increase in concentration marks tumor progression, there is no carbonic anhydrase activity for these tumor markers used in our study. Indeed, CA isoenzymes are important enzymes for body methabolism because they regulate $\mathrm{pH}$ in most tissue. Therefore, in the present study, investigation of effects of certain tumor markers on human erythrocyte carbonic anhydrase I and II, bovine erythrocyte carbonic anhydrase (BCA) and bovine lung carbonic anhydrase (CA-IV) isoenzymes was proposed. In order to conduct this study, HCA-I, HCA-II separately from human erythrocytes, BCA from bovine erythrocytes and CA-IV from bovine lung were purified by Sepharose 4B-L-tyrosine-sulfanylamide affinity chromatography. Prostatic acid phosphatase (PAP) and human chorionic gonadotropin (HCG) as tumor markers were chosen for the investigation of inhibition or activation effects.

For the tumor markers exhibiting the effect, the inhibitor concentrations causing up to $50 \%$ inhibition $\left(\mathrm{I}_{50}\right.$ values $)$ were determined from the regression analysis graph. $I_{50}$ values obtained for of HCA-I, HCA-II, CA-IV and BCA are shown in Table 1.

To show inhibition effects, values of HCA-I, HCA-II, BCA and CA-IV for seven different concentrations of each tumor markers were determined (Figs 1 and 2).

\section{Discussion}

Prostatic acid phosphatase (PAP) is normally present only in small amounts in the blood, but may be found at higher levels in 


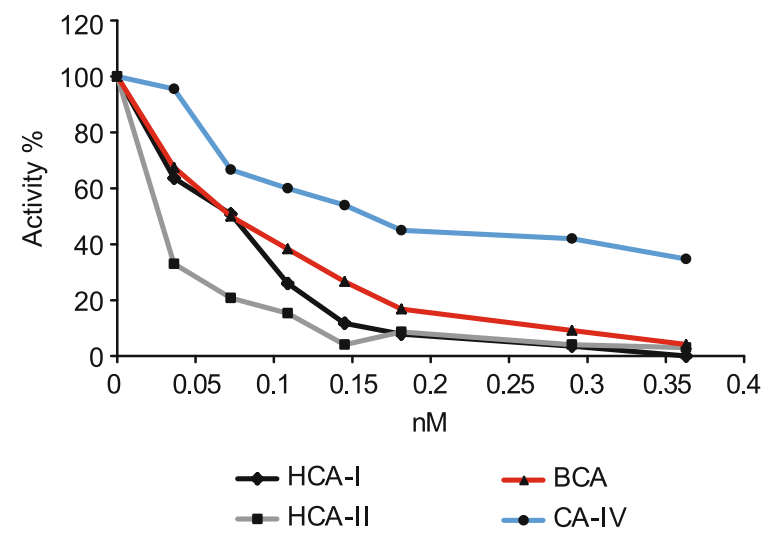

Fig. 1. The effect of prostatic acid phosphatase (PAP) on activity of carbonic anhydrase isoenzymes (HCA-I, HCA-II, BCA and CA-IV).

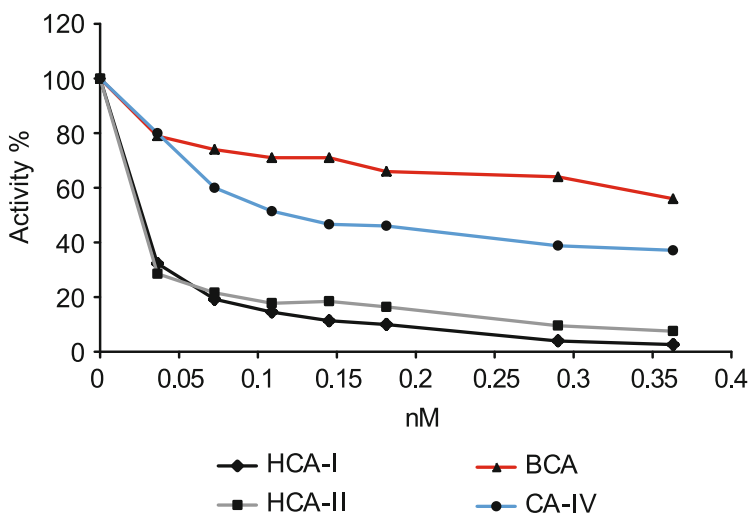

Fig. 2. The effect of human chorionic gonadotropin (HCG) on activity of carbonic anhydrase isoenzymes (HCA-I, HCA-II, BCA and CA-IV).

some patients with prostate cancer, especially if the cancer has spread beyond the prostate. However, blood levels may also be elevated in patients who have certain benign prostate conditions or early stage cancer. Although PAP was originally found to be produced by the prostate, elevated PAP levels have since been associated with testicular cancer, leukemia, and non-Hodgkin's lymphoma, as well as noncancerous conditions such as Gaucher's disease, Paget's disease, osteoporosis, cirrhosis of the liver, pulmonary embolism, and hyperparathyroidism.

Human chorionic gonadotropin (HCG) is normally produced by the placenta during pregnancy. In fact, HCG is sometimes used as a pregnancy test because it increases early within the first trimester. It is also used to screen for choriocarcinoma (a rare cancer of the uterus) in women who are at high risk for the disease, and to monitor the treatment of trophoblastic disease (a rare cancer that develops from an abnormally fertilized egg). Elevated HCG levels may also indicate the presence of cancers of the testis, ovary, liver, stomach, pancreas, and lung. Pregnancy and marijuana use can also cause elevated HCG levels.

It is generally recognized that CA controls the bulk of carbon dioxide exchange between blood and tissues as well as regulation of proton and other ion movements between cells and extracellular fluids. All of the CA isoenzymes are also deeply involved in a great number of secretory activities including fluid movements (20).

\section{Conclusion}

Since CA is a very important enzyme for the body, the inhibition effects of these tumor markers should be considered not only for HCA-I, HCA-II, BCA and CA-IV isoenzymes but also for all CA isoenzymes.

Tumor markers showing inhibitory effects on HCA-I, HCA-II, BCA and CA-IV isoenzymes increase their effect bound to active center of enzymes or other part of enzymes.

The HCG compounds have higher $\boldsymbol{I}_{50}$ values than PAP on HCA-I, HCA-II, CA-IV and BCA. By comparing $\boldsymbol{I}_{50}$ values of the compounds, it has been found that compound $\mathrm{HCG}$ is a more potent inhibitor than PAP on HCA-I, HCA-II, CA-IV and BCA.

\section{References}

1. Hewett-Emmett D, Tashian RE. Functional diversity, conservation, and convergence in the evolution of the alpha-, beta-, and gamma-carbonic anhydrase gene families. Mol Phylogenet Evol 1996; 5: 50-77.

2. Meldrum NU, Roughton FJW. Carbonic anhydrase: Its preparation and properties. J Physiol 1933; 80: 113-142.

3. Stadie WC, O'Brien H. The catalysis of the hydration of carbon dioxide and dehydration of carbonic acid by the enzyme isolated from red blood cells. J Biochem 1933; 103: 521-529.

4. Lindskog S. Carbonic anhydrase. Adv Inorg Biochem 1982; 4: 115-170.

5. Dodgson SJ. The carbonic anhydrases: overview of their importance in cellular physiology and in molecular genetics. In: Dodgson SJ, Tashian RE, Gros G, Carter ND (Eds). The Carbonic Anhydrases: Cellular Physiology and Molecular Genetics. New York: Plenum Press, 1991; 3-14.

6. Sigler K, Hofer M. Mechanism of acid extrusion in yeast. Biochim Biophys Acta 1991; 1071: 375-391.

7. Veitch FP, Blankenship LC. Carbonic anhydrase in bacteria. Nature 1963: 197: 76-77.

8. Shoaf WT, Jones ME. Carbonic anhydrase of microorganisms I: an enzyme from baker's yeast which catalyzes the formation of carbamate from ammonium bicarbonate solutions. Arch Biochem Biophys 1970; 139: $130-142$.

9. Mitsuhashi S, Miyachi S. Amino acid sequence homology between $\mathrm{N}$ - and C-terminal halves of a carbonic anhydrase in Porphyridium purpureum, as deduced from the cloned cDNA. J Biol Chem 1996; 271: 28703-28709.

10. Mulligan ME, Coleman JR. Identification and characterization of a gene encoding a vertebrate-type carbonic anhydrase in cyanobacteria. J Bacteriol 1997; 179: 769-774.

11. Fujikawa AK, Nishimori I, Taguchi T, Onishi S. Human carbonic anhydrase XIV (CA14): cDNA cloning, mRNA expression, and mapping to chromosome 1. Genomics 1999; 61: 74-81.

12. Carter ND, Fryer A, Grand AG, Hume R, Strange RG, Wistrand PJ. Membrane specific carbonic anhydrase (CA-IV) experession in human tissues. Biochem Biophys Acta 1990; 1026: 113-116. 
13. Zhu XL, Sly WS. Carbonic anhydrase IV from human lung. Purification, characterization and comrarison with membrane carbonic anhydrase from human kidney. J Biol Chem 1990; 265: 8795-8801.

14. Arslan O, Nalbantoglu B, Demir N, Ozdemir H, Kufrevioglu OI. A new method for the purification of carbonic anhydrase isoenzymes by affinity chromatography. Turk J Med Sci 1996; 26: 163-166.

15. Laemmli UK. Cleavage of structural proteins during the assembly of the head of bacteriophage. Nature 1970; 227: 680-685.

16. Bradford MM. A rapid and sensitive method for the quantitation of microgram quantites of protein utilizing the principle of protein-dye binding. Annal Biochem 1976; 72: 248-254.

17. Rickli EE, Ghazantar SAS, Gibbons BH, Edsall JT. Carbonic anhydrase from human erythrocytes. J Biol Chem 1964; 239: 1065-1078.
18. Hoechster RM, Kates M, Questel JH. Metabolic inhibitors. Vols 3 and 4 New York: Academic press, 1972; 71-89, 1973; 66-82.

19. Christensen GM, Olson D, Riedel B. Chemical effects on the activity of eight enzymes: A review and discussion relevant to environmental monitoring. Environ Res 1982; 29: 247-255.

20. Botre F, Botre C. 1991: Physiologic implications of carbonic anhydrase facilitated carbon dioxide diffusion coupling to other biometabolic processes. In: Botre FG, Gros, Storey BT (Ed). Carbonic Anhydrase: From Biochemistry and Genetics to Physiology and Clinical Medicine; International Workshop On Carbonic Anhydrase, Spoleto, Italy, March 4-7. Xvi 467 p.

Received April 6, 2014. Accepted January 20, 2015. 